\title{
TIME-VARIABLE EXPRESSION LEVELS OF $m a z F$, atle, sdrH, AND bap GENES DURING BIOFILM FORMATION IN STAPHYLOCOCCUS EPIDERMIDIS
}

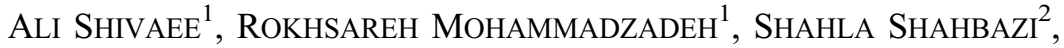 \\ ElAHE PARDAKHTCHI ${ }^{3}$, ElNAZ OHADI ${ }^{1}$ and BEHROOZ SADEGHI KALANI ${ }^{1,3 *}$ \\ ${ }^{1}$ Department of Microbiology, Faculty of Medicine, Iran University of Medical Sciences, \\ Tehran, Iran \\ ${ }^{2}$ Department of Bacteriology, Pasteur Institute of Iran, Teheran, Iran \\ ${ }^{3}$ Microbial Biotechnology Research Center, Iran University of Medical Sciences, \\ Tehran, Iran
}

(Received: 13 March 2019; accepted: 6 May 2019)

\begin{abstract}
Staphylococcus epidermidis is an opportunistic pathogen causing infections related to the usage of implants and medical devices. Pathogenicity of this microorganism is mainly linked to its capability to form biofilm structures. Biofilm formation vastly depends on several factors including different proteins. We studied the expression levels of three proteins including $\mathrm{SdrH}$, Bap, AtlE, and MazF at different time intervals during the course of biofilm formation. In this study, a catheter-derived $S$. epidermidis isolate with strong ability of biofilm formation was selected. PCR assay was used to detect $s d r H$, bap, atlE, and $m a z F$ genes in this isolate. Real-time PCR was used to determine the expression levels of these genes after 4,8 , and $20 \mathrm{~h}$ during the course of biofilm formation. The studied genes showed different expression levels at different time intervals during biofilm formation by real-time PCR method. Expression levels of atlE and $s d r H$ genes were the highest at $4 \mathrm{~h}$, whereas bap gene showed the highest expression level at $8 \mathrm{~h}$ during the course of biofilm formation. In addition, the expression level of $m a z F$ gene peaked at $4 \mathrm{~h}$ and then progressively decreased at 8 and $20 \mathrm{~h}$. Our results suggest the importance of AtlE, SdrH, and MazF proteins in the establishment and development of the biofilm structure. In addition, our results showed the important role of protein Bap in the accumulation of biofilm structure. Future studies are required to understand the exact role of MazF in the process of biofilm formation.
\end{abstract}

Keywords: Staphylococcus epidermidis, biofilm formation, toxin/antitoxin systems, real-time PCR

*Corresponding author; E-mail: Behroz.sadeghi@gmail.com 


\section{Introduction}

Unlike Staphylococcus aureus, the negative coagulase staphylococci are not equipped with a wide range of virulence factors, and their pathogenicity is attributed to the ability of biofilm formation [1, 2]. The potential of the bacterium to adhere to surfaces as well as gaining rapid resistance to most antibiotics are the main pathogenesis strategies adopted by Staphylococcus epidermidis in deviceassociated infections [3]. Biofilm development contributes to bacterial resistance to antibiotic therapy leading to serious challenges in the field of infection treatment [4]. In hospital environments, microbial biofilms form on various surfaces acting as an infection transmission reservoir [5]. The biofilm produced by S. epidermidis initially protects it from the host immune system by preventing the phagocytosis of the bacterium by macrophages and neutrophils. Biofilms also provide a condition for acquiring antibiotic resistance genes and prevent the antibiotic penetration into biofilm structure where an abundance of bacteria is present [6].

The most intensively studied Microbial Surface Components Recognizing Adhesive Matrix Molecules (MSCRAMMs) of S. epidermidis are SdrG that acts as a fibrinogen-binding protein and belongs to the serine/aspartate repeat family proteins (Sdr) [7]. Three members of this family including SdrF, SdrG, and SdrH are present in most $S$. epidermidis strain. The $\mathrm{SdrH}$ protein is involved in some biological processes including the attachment of a cell, either to another cell, or to an underlying substrate, such as the extracellular matrix, via cell adhesion molecules [8]. In addition, autolysin AtlE has been suggested to mediate the primary attachment to the implant surfaces and to bind vitronectin glycoprotein, which is abundantly found in serum, extracellular matrix, and bone leading to infection spread [9]. An important role in biofilm formation has also been attributed to biofilm-associated protein (Bap) [10]. In mice infection model, Bap was involved in the pathogenesis of $S$. aureus, causing a persistent course of infection [11].

Another factor, which has recently been associated with bacterial biofilm formation, is toxin/antitoxin (TA) systems [12]. TA systems include two genes on a single operon encoding a protein toxin and its cognate protein or RNA antitoxin [13]. Six classes of TA systems have been identified so far with type II being the most studied type and having a major role in the emergence of persister cells [14].

In type II TA systems, protein antitoxin is less stable than the protein toxin. In normal conditions, toxin is neutralized by antitoxin, whereas in stress conditions, antitoxin is selectively degraded by proteases such as Lon and clpP, allowing toxin to affect different cellular mechanisms including DNA replication and protein synthesis, subsequently leading to the dampening of cellular metabolism $[15,16]$. Chromosomally encoded TA systems are proposed to be associated with various cellular events, such as programmed cell death, biofilm formation, 
persistence state in the presence of antibiotics, and stabilization of genomic DNA [17]. MazEF is one of the most studied chromosomally encoded TA systems in bacteria, and several researchers have revealed the important physiological roles of MazF homologs [18]. A very few studies have been conducted on the role of these proteins in S. epidermidis. Therefore, the aim of this study was to evaluate the expression levels of genes coding for MazF, AtlE, Bap, and SdrH proteins in a catheter-derived biofilm-producing $S$. epidermidis isolate.

\section{Materials and Methods}

\section{Isolate}

In this study, a $S$. epidermidis isolate with strong ability of biofilm formation, which was previously identified by biochemical tests, was selected. The ability of biofilm formation in this isolate was previously confirmed by Congo red agar and microtiter plate (MTP) method.

\section{PCR amplification}

Total DNA was extracted using Genomic DNA Extraction Kit (Bioneer, Republic of Korea). The presence of $s d r H$, bap, atlE, and $m a z F$ genes in the studied isolate was tested by PCR method, using the primers described in Table I. The PCR reaction mixture with the final volume of $20 \mu \mathrm{l}$ was prepared and DNA amplification was performed in a thermal cycler with denaturation at $94{ }^{\circ} \mathrm{C}$ for 4 min, followed by 30 cycles of denaturation at $94{ }^{\circ} \mathrm{C}$ for $30 \mathrm{~s}$, annealing

Table I. Primer sequences designed for amplification of $s d r G, s d r H$, and $s d r F$ genes

\begin{tabular}{|c|c|c|c|c|}
\hline Genes & Primers $\left(5^{\prime} \rightarrow 3^{\prime}\right)$ & $T_{\mathrm{m}}\left({ }^{\circ} \mathrm{C}\right)$ & $\begin{array}{l}\text { PCR product } \\
\text { size (bp) }\end{array}$ & Reference \\
\hline \multirow[t]{2}{*}{$s d r H$} & F: AGTGGGAACAGCATCAATTTT & 59 & 273 & This study \\
\hline & R: GTGGTAGATTGTACACTTTCTT & & & \\
\hline \multirow[t]{2}{*}{$\operatorname{maz} F$} & F: CAAGGGGGAGTAAGACCTGT & 58 & 95 & [19] \\
\hline & R: TTAATCCTACCAGTAATCGCAGC & & & \\
\hline \multirow[t]{2}{*}{ atle } & F: TCCAAAGCTGTTTACGTTGGT & 58 & 117 & This study \\
\hline & R: TGGTGTTGATTGAGCGTCAG & & & \\
\hline \multirow[t]{2}{*}{ bap } & F: ACCAGAAACGGGTGAAAAAGA & 58 & 178 & This study \\
\hline & R: AAAGGGCTCTCCACCTTTGT & & & \\
\hline \multirow[t]{2}{*}{$16 s r R N A$} & F: CGAACACGTGCTTTGCTTGA & 59 & 152 & This study \\
\hline & R: CCCATACCTGGTCCAACTTCA & & & \\
\hline
\end{tabular}

Note: PCR: polymerase chain reaction; F: forward; R: reverse. 
temperature ( $T_{\mathrm{m}}$ for each primer is shown in Table I) for $30 \mathrm{~s}$, and an extension at $72{ }^{\circ} \mathrm{C}$ for $20 \mathrm{~s}$ with a final extension at $72{ }^{\circ} \mathrm{C}$ for $4 \mathrm{~min}$. S. epidermidis ATCC 35984 was used as a control.

RNA extraction of the biofilm-producing S. epidermidis isolate

For this purpose, according to the MTP protocol, the biofilm-producing isolate was cultured in a solid medium and incubated at $37^{\circ} \mathrm{C}$ for $23 \mathrm{~h}$. Single bacterial colony was then inoculated in 13-ml tryptic soy broth (TSB) medium (Merck, Darmstadt, Germany) containing 1\% glucose (Merck, Darmstadt, Germany) and incubated at $37^{\circ} \mathrm{C}$ for $20 \mathrm{~h}$. In the next step, the standard turbidity inoculum ( $0.5 \mathrm{McF}$ arland) was prepared and $200 \mu \mathrm{l}$ of the suspension was poured into the 96 -well plates and incubated at $38^{\circ} \mathrm{C}$ for $20 \mathrm{~h}$ and after 4,8 , and $18 \mathrm{~h}$, total RNA was isolated using RNA Extraction kit (QIAGEN RNeasy Mini kit, Hilden, Germany), according to the manufacturer's protocol. Extracted RNA was analyzed using a Nanodrop ND1000 (Thermo Fisher Scientific, Lenexa, KS, USA) and on a denaturing $1.5 \%$ TAE-agarose gel $(80 \mathrm{~V}$ for $1 \mathrm{~h})$ to assess its concentration, quality, and integrity. The RNA was DNase treated with RNAse-free DNase (Promega, Madison Wisconsin, USA) (at $37{ }^{\circ} \mathrm{C}$ for $1 \mathrm{~h}$ ). RNA was precipitated with 1 volume of isopropanol and 0.1 volume of $3 \mathrm{M} \mathrm{NaOAc}(\mathrm{pH}$ 4.6). The suspension was incubated on ice for $20 \mathrm{~min}$ and centrifuged at high speed at $4{ }^{\circ} \mathrm{C}$ for $30 \mathrm{~min}$. The RNA pellet was dried and resuspended with RNasefree MilliQ H2O (Sigma Aldrich, Darmstadt, Germany), according to the manufacturer's instructions. The control sample was placed in a microtube containing TSB (Merck, Darmstadt, Germany) (without glucose) at $37{ }^{\circ} \mathrm{C}$.

Quantitative real-time polymerase chain reaction for genes responsible for biofilm production in $\mathrm{S}$. epidermidis isolate

About $500 \mathrm{ng}-1 \mu \mathrm{g}$ of RNA was converted into cDNA using AccuPower CycleScript RT PreMix (Bioneer). Quantitative real-time PCR was performed in a Rotor-Gene thermal cycler (Corbett 6000; Australia) using SYBR Green method (AccuPower Green Star qPCR Master Mix; Bioneer). A total volume of $20 \mu 1$ reaction containing $2 \mu \mathrm{l}$ of cDNA, $12.5 \mu \mathrm{l}$ SYBR Green master mix (SigmaAldrich, Germany), $4.5 \mu \mathrm{l}$ nuclease-free water, and $1 \mu \mathrm{l}$ of each primer ( $5 \mathrm{pmol}$; forward and reverse) was run according to the following program: an initial activation step at $94{ }^{\circ} \mathrm{C}$ for $4 \mathrm{~min}, 35$ cycles of denaturation at $94{ }^{\circ} \mathrm{C}$ for $30 \mathrm{~s}$, annealing at $59{ }^{\circ} \mathrm{C}$ for $30 \mathrm{~s}$, and extension at $72{ }^{\circ} \mathrm{C}$ for $20 \mathrm{~s}$. $16 \mathrm{~s}$ rRNA gene (Table I) was used as an internal control to normalize target gene expression 
measurements. Each test was performed in triplicates, independently. Real-time PCR results were analyzed using the 2[-Delta Delta C(T)] method [20].

\section{Results}

In order to investigate the presence of genes involved in biofilm formation including $s d r H$, bap, atlE, and $m a z F$ toxin in the studied $S$. epidermidis isolate, specific primers were designed for these genes. The expected PCR band sizes for $s d r H$, bap, atlE, and $m a z F$ genes were 273, 178, 117, and 95 bp, respectively, which were observed in the studied isolate. In real-time PCR assay, the studied genes showed different expression levels at different time intervals during biofilm formation. After $4 \mathrm{~h}, m a z F$, atlE, and $s d r H$ genes showed the highest expression levels, whereas bap gene showed the highest expression levels after $8 \mathrm{~h}$. Expression levels of genes during biofilm formation are illustrated in Figure 1.

\section{Discussion}

Staphylococcus epidermidis is commonly known as a commensal microorganism prevalently residing on the human skin. Nonetheless, this microorganism can turn into an invasive pathogen under certain circumstances, such as implantation of medical devices or concomitant medical conditions [21]. Hence, this bacterium is considered as an opportunistic pathogen with the ability of causing

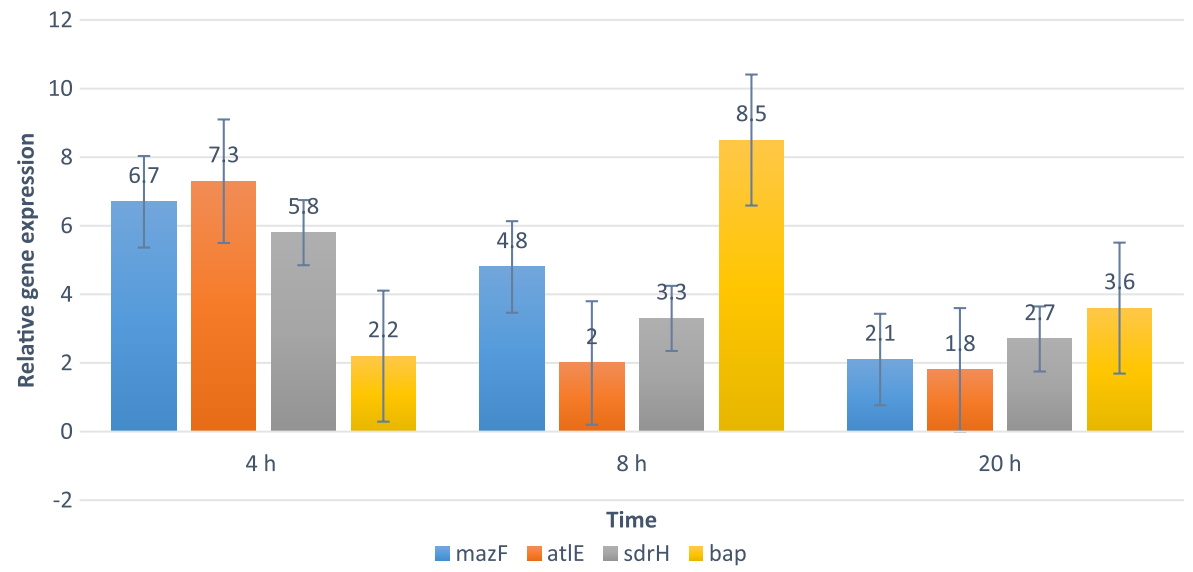

Figure 1. Gene expression analysis of mazF toxin, bap, $s d r H$, and atlE by real-time PCR during biofilm formation at 4,8 , and $20 \mathrm{~h}$. Relative expression is normalized with housekeeping gene $16 \operatorname{sr} N A$ ( $p$ value $<0.01)$ 
hospital-acquired infections including blood infections associated with catheter use. Infections caused by $S$. epidermidis are mostly attributed to its ability of biofilm formation.

The process of biofilm formation is commonly categorized in three steps including primary attachment, accumulative phase, and disassembly step [22]. Initiation of device-related infections requires a strong bacterial attachment to the foreign materials. AtlE is a protein belonging to the peptidoglycan hydrolase family with a crucial role in the degradation of bacterial cell wall [23]. In this study, atlE expression was at its highest level after $4 \mathrm{~h}$ and its expression level decreased from 4 to $20 \mathrm{~h}$.

Many studies have been conducted on the expression level of atlE gene during biofilm formation. The results of the study conducted by Vandecasteele et al. [24] showed that the constant expression of altE in S. epidermidis isolate may suggest the role of the encoded protein during the entire course of infection caused by this bacterium. In another study conducted by Patel et al., altE expression was at its highest level after $2 \mathrm{~h}$. However, its expression decreased gradually from 2 to $12 \mathrm{~h}$. They showed that AtlE may play a pivotal role in the development of bacterial colonization and the initiation of a device-related infection [25]. Their result was in accordance with the result of this study, which showed a higher atlE expression at the initial steps of biofilm formation. Therefore, it is suggested that AtlE protein is involved in binding of bacterium to foreign surfaces and the establishment of biofilm structure. In fact, it is suggested that $S$. epidermidis uses AtlE protein to attach to surface organized vitronectin (an extracellular matrix material) [22].

Another factors expressed by S. epidermidis, which are involved in biofilm formation, belong to the group of serine-aspartate repeat proteins (Sdr). These proteins are thoroughly investigated and are considered as a protein family of MSCRAMMs. Three of these Sdr proteins have been identified in S. epidermidis, including SdrF, SdrG, and SdrH [8]. Many studies have been conducted to determine the role of Sdr proteins during the course of biofilm formation in S. epidermidis. Hartford et al. [26] showed the role of SdrG in the attachment of S. epidermidis to surfaces covered with fibrinogen. Arrecubieta et al. showed the involvement of SdrF in cardiac implant-associated infections. They also showed that protein is responsible for the attachment of bacteria to unmodified Dacron surfaces [27]. In this study, we investigated the expression of SdrH protein, which is mostly found in biofilm-producing isolates of $S$. epidermidis. Similar to the results of atlE expression, expression of $s d r H$ gene was at the highest level during the first hours of biofilm formation $(4 \mathrm{~h}$ ) and decreased with time (from 4 to $20 \mathrm{~h}$ ), which is indicative of the potential role of $\mathrm{SdrH}$ protein in the initial attachment of bacterium to the surface. 
The presence of Bap has also been confirmed in S. epidermidis isolates, especially in invasive biofilm-producing isolates. The role of biofilm-associated protein Bap has been investigated in $S$. aureus isolates. Taglialegna et al. [28] showed that Bap protein assembles itself to form aggregates of active amyloid with the ability of building biofilm matrix under harsh environmental conditions. In this study, the expression level of bap gene was at its highest level after $8 \mathrm{~h}$ during biofilm formation. This suggests that Bap contributes to the accumulation of biofilm in biofilm-producing $S$. epidermidis isolates.

Lewis et al. showed the role of biofilm formation in the survival of bacterial persistence cells. In fact, the components of host immune system and antibiotics cannot reach these cells as they are embedded in the structure of biofilms. These cells can further repopulate and spread causing infection recurrences. Several bacterial functions have been attributed to TA systems including programmed cell death, persistence cell formation, and biofilm formation. Many studies have attempted to determine the exact role of TA systems in biofilm formation. MqsR/MqsA was reportedly the first TA system, which directly affected biofilm formation in E. coli strains [29]. This TA system interferes with quorum-sensing system and motility pathways [30]. MqsA antitoxin reportedly reduces biofilm formation by suppressing RpoS and CsgD regulators and subsequently reducing cdi-GMP, which is considered as a signaling nucleotide [31]. Under oxidative stress, MqsA is degraded by Lon protease, which further triggers bacterial biofilm formation [32].

Many TA modules have been identified in E. coli one of those is the wellcharacterized MazEF system. MazF toxin acts as an endoribonuclease enzyme with the ability of cleaving mRNAs at ACA sequences. The exact role of MazEF system in biofilm formation remains controversial. It has been previously reported that mutation in MazEF TA module can decrease biofilm formation [33]. It has been previously suggested that programmed cell death provides the vital nutrition for cells present in biofilm structure as diffusion of nutrition is limited. MazEF TA module has been linked to programmed cell death. Therefore, it is hypothesized that MazEF can participate in biofilm formation through its association with programmed cell death [34].

In this study, after confirming the presence of $m a z F$ gene in the biofilmproducing $S$. epidermidis isolate, we measured the expression levels of this gene during biofilm formation. After $2 \mathrm{~h}$, the expression of this gene was at its highest level and expression decreased during 8 and $20 \mathrm{~h}$ of biofilm formation. This may suggest that MazF may be involved in the course of the initial establishment of biofilm formation. However, more studies need to be conducted to understand the exact role of this TA module in biofilm formation. 
In conclusion, $S$. epidermidis is mainly associated with infections due to the usage of implants and medical devices. Virulence of this microorganism is majorly linked to its capability of biofilm formation. Biofilm formation vastly depends on different factors among which are several proteins that facilitate this process. We studied the expression of three proteins including SdrH, Bap, and AtlE at different time intervals during biofilm formation. We also studied the expression of MazF protein, which is the toxin component of MazEF TA module. This study showed the highest expression of $s d r H$, atlE, and $m a z F$ genes after $4 \mathrm{~h}$ during biofilm formation. This suggests the importance of their encoded proteins in the establishment and development of the biofilm structure. However, Bap-encoding gene showed the highest expression level after $8 \mathrm{~h}$ during the biofilm formation, which is suggestive of its role in the accumulation of biofilm structure. Future studies are required to understand the exact role of $\mathrm{MazF}$ in the process of biofilm formation.

\section{Acknowledgements}

The authors would like to thank all the professors who helped us in this project in the Department of Microbiology, Iran University of Medical Sciences.

\section{Conflict of Interest}

The authors declare no competing interests.

\section{References}

1. Otto, M.: Staphylococcus epidermidis - The 'accidental' pathogen. Nat Rev Microbiol 7, 555 (2009).

2. Kalani, B. S., Khodaei, F., Moghadampour, M., Lotfollahi, L., Ohadi, E., Foroozeshfard, M., Shivaee, A., Irajian, G.: TRs analysis revealed Staphylococcus epidermidis transmission among patients and hospital. Ann Ig 31, 52-61 (2019).

3. Becker, K., Heilmann, C., Peters, G.: Coagulase-negative staphylococci. Clin Microbiol Rev 27, 870-926 (2014).

4. Fey, P. D., Olson, M. E.: Current concepts in biofilm formation of Staphylococcus epidermidis. Future Microbiol 5, 917-933 (2010).

5. von Eiff, C., Peters, G., Heilmann, C.: Pathogenesis of infections due to coagulase negative staphylococci. Lancet Infect Dis 2, 677-685 (2002).

6. Schommer, N. N., Christner, M., Hentschke, M., Ruckdeschel, K., Aepfelbacher, M., Rohde, H.: Staphylococcus epidermidis uses distinct mechanisms of biofilm formation to interfere with phagocytosis and activation of mouse macrophage-like cells 774A.1. Infect immun 79, 2267-2276 (2011). 
7. Davis, S. L., Gurusiddappa, S., McCrea, K. W., Perkins, S., Höök, M.: SdrG, a fibrinogenbinding bacterial adhesin of the microbial surface components recognizing adhesive matrix molecules subfamily from Staphylococcus epidermidis, targets the thrombin cleavage site in the B $\beta$ chain. J Biol Chem 276, 27799-27805 (2001).

8. McCrea, K. W., Hartford, O., Davis, S., Eidhin, D. N., Lina, G., Speziale, P., Foster, T. J., Höök, M.: The serine-aspartate repeat (Sdr) protein family in Staphylococcus epidermidis. Microbiology 146, 1535-1546 (2000).

9. Qin, Z., Ou, Y., Yang, L., Zhu, Y., Tolker-Nielsen, T., Molin, S., Qu, D.: Role of autolysinmediated DNA release in biofilm formation of Staphylococcus epidermidis. Microbiology 153, 2083-2092 (2007).

10. Latasa, C., Solano, C., Penadés, J. R., Lasa, I.: Biofilm-associated proteins. C R Biol 329, 849-857 (2006).

11. Lasa, I., Penadés, J. R.: Bap: A family of surface proteins involved in biofilm formation. Res Microbiol 157, 99-107 (2006).

12. Wen, Y., Behiels, E., Devreese, B.: Toxin-antitoxin systems: Their role in persistence, biofilm formation, and pathogenicity. Pathog Dis 70, 240-249 (2014).

13. Kalani, B. S., Irajian, G., Lotfollahi, L., Abdollahzadeh, E., Razavi, S.: Putative type II toxin-antitoxin systems in Listeria monocytogenes isolated from clinical, food, and animal samples in Iran. Microb Pathog 122, 19-24 (2018).

14. Page, R., Peti, W.: Toxin-antitoxin systems in bacterial growth arrest and persistence. Nat Chem Biol 12, 208 (2016).

15. Rogers, A., Townsley, L., Gallego-Hernandez, A. L., Beyhan, S., Kwuan, L., Yildiz, F. H.: The LonA protease regulates biofilm formation, motility, virulence, and the type VI secretion system in Vibrio cholerae. J Bacteriol 198, 973-985 (2016).

16. Donegan, N. P., Thompson, E. T., Fu, Z., Cheung, A. L.: Proteolytic regulation of toxinantitoxin systems by ClpPC in Staphylococcus aureus. J Bacteriol 192, 1416-1422 (2010).

17. Lobato-Márquez, D., Díaz-Orejas, R., Garcia-del Portillo, F.: Toxin-antitoxins and bacterial virulence. FEMS Microbiol Rev 40, 592-609 (2016).

18. Engelberg-Kulka, H., Hazan, R., Amitai, S.: mazEF: A chromosomal toxin-antitoxin module that triggers programmed cell death in bacteria. J Cell Sci 118, 4327-4332 (2005).

19. Behrooz, S. K., Lida, L., Ali, S., Mehdi, M., Rasoul, M., Elnaz, O., Farid, B. T., Gholamreza, I.: Study of MazEF, sam, and phd-doc putative toxin-antitoxin systems in Staphylococcus epidermidis. Acta Microbiol Immunol Hung 65, 81-91 (2018).

20. Livak, K. J., Schmittgen, T. D.: Analysis of relative gene expression data using real-time quantitative PCR and the 2- $\Delta \Delta$ CT method. Methods 25, 402-408 (2001).

21. Uckay, I., Pittet, D., Vaudaux, P., Sax, H., Lew, D., Waldvogel, F.: Foreign body infections due to Staphylococcus epidermidis. Ann Med 41, 109-119 (2009).

22. Büttner, H., Mack, D., Rohde, H.: Structural basis of Staphylococcus epidermidis biofilm formation: Mechanisms and molecular interactions. Front Cell Infect Microbiol 5, 14 (2015).

23. Biswas, R., Voggu, L., Simon, U. K., Hentschel, P., Thumm, G., Götz, F.: Activity of the major staphylococcal autolysin Atl. FEMS Microbiol Lett 259, 260-268 (2006).

24. Vandecasteele, S. J., Peetermans, W. E., Merckx, R., Eldere, J. V.: Expression of biofilmassociated genes in Staphylococcus epidermidis during in vitro and in vivo foreign body infections. J Infect Dis 188, 730-737 (2003).

25. Patel, J. D., Colton, E., Ebert, M., Anderson, J. M.: Gene expression during S. epidermidis biofilm formation on biomaterials. J Biomed Mater Res A 100, 2863-2869 (2012). 
26. Hartford, O., O’Brien, L., Schofield, K., Wells, J., Foster, T. J.: The Fbe (SdrG) protein of Staphylococcus epidermidis HB promotes bacterial adherence to fibrinogen. Microbiology 147, 2545-2552 (2001).

27. Arrecubieta, C., Toba, F. A., von Bayern, M., Akashi, H., Deng, M. C., Naka, Y., Lowy, F. D.: SdrF, a Staphylococcus epidermidis surface protein, contributes to the initiation of ventricular assist device driveline-related infections. PLoS Pathog 5, e1000411 (2009).

28. Taglialegna, A., Navarro, S., Ventura, S., Garnett, J. A., Matthews, S., Penades, J. R., Lasa, I., Valle, J.: Staphylococcal Bap proteins build amyloid scaffold biofilm matrices in response to environmental signals. PLoS Pathog 12, e1005711 (2016).

29. Kasari, V., Kurg, K., Margus, T., Tenson, T., Kaldalu, N.: The Escherichia coli mqsR and ygiT genes encode a new toxin-antitoxin pair. J Bacteriol 192, 2908-2919 (2010).

30. Barrios, A. F. G., Zuo, R., Hashimoto, Y., Yang, L., Bentley, W. E., Wood, T. K.: Autoinducer 2 controls biofilm formation in Escherichia coli through a novel motility quorum-sensing regulator (MqsR, B3022). J Bacteriol 188, 305-316 (2006).

31. Soo, V. W., Wood, T. K.: Antitoxin MqsA represses curli formation through the master biofilm regulator CsgD. Sci Rep 3, 3186 (2013).

32. Wang, X., Wood, T. K.: Toxin-antitoxin systems influence biofilm and persister cell formation and the general stress response. Appl Environ Microbiol 77, 5577-5583 (2011).

33. Kim, Y., Wang, X., Ma, Q., Zhang, X.-S., Wood, T. K.: Toxin-antitoxin systems in Escherichia coli influence biofilm formation through YjgK (TabA) and fimbriae. J Bacteriol 191, 1258-1267 (2009).

34. Kolodkin-Gal, I., Verdiger, R., Shlosberg-Fedida, A., Engelberg-Kulka, H.: Correction: A differential effect of $E$. coli toxin-antitoxin systems on cell death in liquid media and biofilm formation. PLoS One 10, e0140184 (2015). 